\title{
LOS EXPEDIENTES-OPOSICIÓN A DIRECCIONES DE ESCUELAS GRADUADAS DE 1932 COMO FUENTE HISTÓRICO-EDUCATIVA. UN ESTUDIO DE CASO: EL EXPEDIENTE-OPOSICIÓN DE MARÍA SÁNCHEZ ARBÓS ${ }^{\alpha}$
}

\begin{abstract}
The personal files from public exams to become a headmaster of graded schools in 1932 as a source for history of education. A case study: the dossier of María Sánchez Arbós
\end{abstract}

\section{Carlos Menguiano Rodríguez ${ }^{\beta}$}

Fecha de recepción: 06/05/2018 • Fecha de aceptación: 16/06/2018

Resumen. El objetivo de este artículo es presentar y contextualizar una fuente original hasta ahora desatendida y carente de un estudio sistemático. Se trata de los expedientes-oposición de las oposiciones a Direcciones de escuelas graduadas de seis o más secciones de 1932, las únicas convocadas por la Segunda República Española para este cuerpo. La particular estructura de estas oposiciones nos sugiere una propuesta metodológica para trabajar estos expedientes: se trata de considerar cada expediente-oposición como una práctica de archivo de vida, donde cada opositor selecciona, con cierta libertad, una serie de fragmentos y documentos mediante los cuales construye y representa su identidad profesional ante el tribunal, pero también ante sí mismo. Por último, llevaremos a cabo un estudio de caso con el expediente de una de las opositoras más conocidas: María Sánchez Arbós. Este caso nos permite, además, medir las posibilidades metodológicas de nuestra propuesta para estudiar la construcción y reconstrucción de las identidades

\footnotetext{
a Este artículo ha sido posible gracias a la financiación concedida al proyecto I+D «La fotografía escolar en colecciones documentales de ámbito estatal (1900-1970)» [EDU2014-52498-C2-1-P y BES-2015-075107], subvencionado por el Ministerio de Economía, Industria y Competitividad.

B Departamento de Ciencias de la Educación. Facultad de Educación. Universidad de Alcalá. Aulario María de Guzmán. C/ San Cirilo, s/n. 28801 Alcalá de Henares. España. carlos.menguianorodr@uah.es (D) https://orcid.org/0000-0003-0823-6141
}

Cómo citar este artículo: Menguiano Rodríguez, Carlos. «Los expedientes-oposición a direcciones de escuelas graduadas de 1932 como fuente histórico-educativa. Un estudio de caso: el expediente-oposición de María Sánchez Arbós». Historia y Memoria de la Educación 10 (2019): 309-344 
profesionales de los docentes republicanos, al tener la oportunidad de comparar la composición del expediente-oposición, elaborada en 1932, con otra fuente muy conocida: su Diario, publicado en los años sesenta.

Palabras clave: Archivo de vida; Expedientes-de oposición; Educación republicana; María Sánchez Arbós.

Abstract. The aim of this paper is to present and contextualize a new source that, until now, had remained ignored and in need of a systematic approach: the personal files from public exams for the post of headmaster of large graded schools in 1932. These were the only such exams convened during the Second Spanish Republic. The peculiar structure of the exams opens the path to a new methodological approach, consisting of treating each file as a life-archive practice in which every candidate selects, with considerable freedom, a series of fragments and documents with which they would construct and represent their professional identities, not only to the examining board but also to themselves. Lastly, this paper undertakes a case-study with the file of well-known teacher, María Sánchez Arbós. This case will allow us to gauge the methodological possibilities of our proposal for studying the construction and reconstruction of the professional identities of republican teachers by having the opportunity to compare the composition of her exam file elaborated in 1932 with another well-known source: her diary, which was published in the nineteen sixties.

Keywords: Life-archive practice; Public exams files; Republican education; María Sánchez Arbós.

\section{INTRODUCCIÓN}

En el marco de la investigación histórica, la presentación de una nueva fuente debe ir siempre seguida de una reflexión acerca de su contexto, su valor, su uso y los resultados que posibilita. Por ello, este artículo tiene como fin la contextualización y valoración de una fuente original que actualmente estamos trabajando: los expedientes-oposición pertenecientes al concurso-oposición para adjudicar plazas de directores y directoras de grandes escuelas graduadas, convocado en diciembre del año 1932. A esto sumaremos la propuesta de un marco teórico acorde con las características de dicha fuente y sus posibilidades para el estudio del magisterio primario republicano.

Nuestro primer objetivo será la contextualización de este concurso-oposición. Las oposiciones a Direcciones de escuela graduada de las 
que nos ocupamos forman parte de los procesos de selección de cuerpos docentes selectos promovidos por el gobierno republicano, los cuales serían de vital importancia para la renovación del magisterio primario durante la Segunda República. Sin embargo, la poca atención que ha recibido dicho cuerpo de directores ${ }^{1}$ de escuela graduada nos hace preguntarnos: ¿Por qué podrían considerarse las direcciones de graduadas como cuerpo de especial atención en el contexto republicano? Sólo cuando respondamos a esta pregunta entenderemos por qué dichas oposiciones resultaron tan atractivas para un surtido número de docentes que, con diferentes perfiles, edades, preparación académica y experiencias profesionales, se vieron llamados a participar en ellas.

Una vez comprendida la importancia de dicho cuerpo, su papel en el ideario pedagógico republicano y su vinculación con el proceso de renovación pedagógica que el nuevo régimen fomentaba, nos preguntaremos por la especificidad de esta fuente: ¿qué la hace tan particular? Pasaremos entonces a analizar dichas oposiciones y lo que hace de ellas una fuente peculiar para el periodo que estudiamos: se trata del modo singular de construir los expedientes, bajo una exigencia narrativa a la que todos los aspirantes se veían impelidos. Trataremos de comprender cómo el característico modo de producción de estos expedientes hace de ellos una fuente valiosa para estudiar las prácticas y los discursos vigentes en la realidad educativa española de las primeras décadas del siglo $\mathrm{XX}$ desde la perspectiva privilegiada de uno de sus principales actores y productores: el magisterio primario en activo.

Ahora bien, las condiciones determinadas de producción de estos expedientes, la heterogeneidad que presentan y la diversidad de materiales

\footnotetext{
${ }^{1}$ Es preciso aclarar que no utilizamos el término «cuerpo» en un sentido jurídico cuando nos referimos a las direcciones escolares, sino como expresión de una mentalidad propia de quienes ejercían o aspiraban a ejercer esos puestos, cuyos rasgos diferenciales eran potenciados por las funciones jerárquicas del director de graduada en la realidad escolar, los procesos selectivos y formativos proyectados por la República para estos cargos y la percepción de su relevancia en la reforma educativa. Sin embargo, a efectos estrictamente jurídicos, no existía en los años 30 un cuerpo profesional específico para los directores de escuelas graduadas, pues formaban parte del mismo escalafón general que el resto de los docentes primarios y solo recibían un emolumento por el desempeño de las funciones directoras. A este respecto, la historia educativa española solo cuenta con un efímero ensayo de un cuerpo profesional independiente, el del Cuerpo de Directores Escolares de 1967 (véase Antonio Viñao Frago, «La Dirección Escolar: un análisis genealógico-cultural», Educação 27, no. 2 (2004): 384-388; también publicado en Mariano Fernández Enguita y Marta Gutiérrez Sastre (coords.), Organización escolar, profesión docente y entorno comunitario (Madrid, Universidad Internacional de Andalucía / Ediciones Akal, 2005), 35-81.
} 
que proporcionan, nos obliga también a preguntarnos: ¿qué propuesta metodológica nos permite trabajar esta fuente? ¿Sobre qué marco interpretativo podemos analizarla? Nuestra propuesta es la siguiente: podemos entender la composición de estos expedientes-oposición como una práctica de archivo de vida mediante la cual, cada aspirante representa, con cierto margen de libertad, una identidad profesional. Esta noción de archivo de vida delimita un marco hermenéutico desde el cual podemos hacernos cargo de la pluralidad de materiales presentados, al poner énfasis en la significatividad de cada decisión al representar la propia vida y de su valor para el análisis de la autopercepción de estos docentes, así como la construcción de sus discursos pedagógicos.

En último lugar, ofreceremos un estudio de caso de uno de estos expedientes: el de María Sánchez Arbós. Con él trataremos de evaluar el tipo de análisis y de resultados que permite nuestra propuesta, así como las estrategias que pueden seguir a este análisis. En este último sentido, el caso de María Sánchez Arbós nos permitirá hacer una comparación con un tipo de fuente similar: su Diario publicado. Una lectura comparativa de este tipo permite escenificar con claridad la toma de decisiones que implica la construcción del expediente-oposición y su coligada representación de una identidad profesional.

Mediante este estudio de caso, pretendemos operativizar las posibilidades de nuestra propuesta, marcar un plan de trabajo para el estudio de la fuente en su integridad y avanzar sus potenciales resultados.

\section{EL CONTEXTO DE LAS OPOSICIONES}

El 16 de abril de 1931, dos días después de la proclamación de la Segunda República Española, aparecía en el periódico Crisol una columna de Rodolfo Llopis Ferrándiz, ${ }^{2}$ quien ese mismo día acababa de ser nombrado Director General de Primera Enseñanza, donde proclamaba:

\footnotetext{
${ }^{2}$ Llopis fue Director General de Enseñanza Primaria de 1931 a 1933 y una de las figuras significativas en el desarrollo de la política educativa del primer bienio republicano. Su influencia y responsabilidad en las reformas emprendidas por el Ministerio de Instrucción Pública y Bellas Artes han sido reconocidas en obras esenciales centradas en este periodo. Véase su presencia en la obra de Antonio Molero Pintado, La reforma educativa de la Segunda República Española. Primer bienio (Madrid: Santillana, 1977), en la de Claudio Lozano Seijas, La Educación Republicana 1931-1939 (Barcelona: Universidad de Barcelona, 1980), o las páginas dedicadas a su perfil en Mercedes Samaniego Boneu, La Política Educativa de la Segunda República durante el Bienio Azañista (Madrid: CSIC, 1977), 185-214.
} 
La República, tiene que hacer maestros nuevos. Los maestros que necesita el país en esta hora decisiva. Pero tiene además que utilizar a los maestros actuales. Ese ha de ser uno de los problemas más delicados del nuevo régimen. ${ }^{3}$

Efectivamente, uno de los problemas educativos más importantes para el nuevo gobierno sería el de la formación y selección del magisterio primario que debía llenar las aulas de la nueva escuela republicana. Con la sustitución de las antiguas oposiciones de ingreso por los cursillos de selección profesional (Decreto de 3 de Julio de 1931, Gaceta del 4) se pretendía resolver este primer problema de selección de la base magisterial de primera enseñanza.

Sin embargo, quedaba todavía una cuestión de extrema urgencia: era necesario decidir cuál sería el sistema de formación y selección de los cuerpos especiales de la primera enseñanza que debían liderar la transformación y renovación pedagógica proyectada por el Ministerio. Nos referimos a la Inspección de Primera enseñanza y a las Direcciones de Escuelas graduadas. La creación de la Sección de Pedagogía, dispuesta por Decreto de 27 de enero de 1932 (Gaceta del 29) en sustitución de la Escuela Superior de Magisterio, respondía a esta necesidad. Así, puede leerse en su primer artículo:

Artículo $1^{\circ}$. Para el cultivo de las ciencias de la educación y el desarrollo de los estudios superiores pedagógicos y para la formación del Profesorado de la Segunda enseñanza y Escuelas Normales, Inspección de Primera enseñanza y Directores de grandes Escuelas graduadas, se crea en la Facultad de Filosofía y Letras de la Universidad de Madrid una Sección de Pedagogía. ${ }^{4}$

No obstante, eran muchas las plazas de nueva creación que apremiaba designar, tanto de Inspección como de Direcciones de grandes Grupos Escolares, y la incipiente Sección de Pedagogía apenas comenzaba a funcionar. Luego era imperioso emprender reformas en los procesos de selección de estos cuerpos selectos, que se materializaron en dos distintos decretos:

\footnotetext{
${ }^{3}$ Rodolfo Llopis, «Lo que hará la República», Crisol (Madrid), 16 de abril de 1931. Subrayado nuestro.

${ }^{4}$ Gaceta de Madrid (29 enero 1932): 732.
} 
$1^{\circ}$ ) El Decreto de 2 de octubre de 1931 (Gaceta del 3), que regulaba el ingreso en la Inspección y que sería incorporado con leves variaciones en el posterior Reglamento orgánico de la inspección de Primera enseñanza, publicado por Decreto el día 2 de diciembre de 1932.

$2^{\circ}$ ) El Decreto de 1 de julio de 1932 (Gaceta del 5), donde se regulaba la provisión de destinos que no fuesen de nuevo ingreso y en cuyo preámbulo se anunciaban "profundas innovaciones ${ }^{5}$ en la provisión de Direcciones de graduadas.

En ambas regulaciones se establecían numerosos cambios, entre los cuales se incluían modificaciones para la selección del personal para estos cuerpos clave en la enseñanza primaria.

En este punto, conviene anticipar una reflexión. Hay un consenso más o menos establecido en la historiografía educativa de la etapa republicana a la hora de comprender la reorganización de la Inspección de enseñanza como uno de los hitos de la reforma educativa. ${ }^{6}$ Antonio Molero justifica este interés al señalar que «los inspectores significaron para cualquier régimen un magnífico instrumento de influencia directa sobre escuelas y maestros $»^{7}$ y, por tanto, que «la Inspección, como encrucijada donde se citan lo político y lo técnico, iba a ser una buena piedra de toque para el Gobierno instaurado el 14 de abril de $1931 » .8$ El mismo autor entiende como punto relevante de esta reorganización las nuevas medidas adoptadas sobre los procesos de selección, que contribuían a que la Inspección ocupase un puesto de vanguardia en toda la máquina docente. No obstante, este interés por la reorganización de la Inspección contrasta con la escasa atención que han recibido las Direcciones de los Grandes Grupos escolares. Por ello nos preguntamos: ¿Qué hacía que la dirección de una graduada mereciese los cuidados y atenciones dispuestos en la Gaceta? En definitiva, ¿por qué podría considerarse, al menos

\footnotetext{
${ }^{5}$ Gaceta de Madrid (5 Julio 1932): 119.

- Véase Molero, La reforma educativa de la Segunda República Española, 98-100 y 344-346; Samaniego, La Política Educativa de la Segunda República, 208-211, o Mariano Pérez Galán, La enseñanza en la Segunda República (Madrid: Biblioteca Nueva, 2011), 139-142.

${ }_{7}^{7}$ Molero, La reforma educativa de la Segunda República Española, 98.

${ }_{8}$ Molero, La reforma educativa de la Segunda República Española, 98, cita 27.
} 
programáticamente, a los directores y directoras de escuela graduada como un grupo clave en la reforma republicana?

\section{Las Direcciones de escuelas graduadas como cuerpo selecto de docentes en la Segunda República}

Con el fin de responder a las preguntas anteriores, consideramos prudente y justificado atender a la importancia de las Direcciones de escuelas graduadas en el contexto educativo republicano. Como ya hemos mencionado, son muchos los estudios clásicos del periodo republicano que reparan en la importancia de la reorganización de la Inspección de Primera enseñanza. En contraste, cabe advertir, en estos mismos estudios, la marcada ausencia de aquella figura tan particular: el director de escuela graduada. Esto nos sorprende menos cuando nos percatamos de que, por lo general, el estudio específico de la escuela graduada suele pasar desapercibido, cuando no simplemente omitido, en los estudios genéricos de esta etapa de nuestra historia educativa. ${ }^{9}$

A pesar de lo dicho, no faltan testimonios que se hagan eco de la importancia programática de la escuela graduada en dicho periodo. Si atendemos, por ejemplo, a las Ideas para una reforma constitucional de la educación pública promulgadas por Lorenzo Luzuriaga en la Revista de Pedagogía en abril de 1931, podemos leer en la séptima de ellas:

$7^{\mathrm{a}}$. Para la creación de las diversas instituciones educativas, se tendrán en cuenta las siguientes consideraciones [...] Las escuelas básicas se crearán a razón de cuarenta niños de matrícula en edad escolar, de seis a doce años, tendiéndose en el campo a establecerlas en los núcleos centrales o de mayor población, y a reducir lo más posible, las escuelas unitarias, introduciéndose la graduación en todas ellas. En las poblaciones, no habrá ninguna escuela sin un mínimo de tres grados y un máximo de doce, en dos series de clases paralelas. ${ }^{10}$

\footnotetext{
${ }_{9}$ Encontramos una sucinta excepción en Lozano, La educación republicana, 81-82.

${ }^{10}$ Lorenzo Luzuriaga, La escuela nueva pública (Buenos Aires: Losada, 2002), 231. Subrayado nuestro.
} 
Hallamos el mismo énfasis en las medidas tomadas por el Comité revolucionario que orientarían el «programa pedagógico» del Gobierno Provisional. La primera de ellas, según Rodolfo Llopis, decía: «1 ${ }^{\circ}$. Se procederá inmediatamente a dotar a los pueblos del número de escuelas, así maternales como primarias, que el censo de población exija, procurando que estas últimas sean graduadas». ${ }^{11}$

Por consiguiente, sabemos que muchos de los ideólogos pedagógicos republicanos apostaban claramente por la escuela graduada como ideal organizativo de la escuela pública. Asimismo, el Ministerio de Instrucción Pública y Bellas Artes republicano hizo lo posible por impulsar su desarrollo e implantación. De hecho, la escuela graduada se vio beneficiada por la política de construcciones escolares del gobierno republicano: ${ }^{12}$ se subvencionaron multitud de grandes Grupos Escolares en ciudades como Madrid ${ }^{13}$ y en otras tantas poblaciones donde el censo lo permitía, mediante los créditos de «Obras del Plan general Nacional de Cultura», concedidos por el Ministerio de Hacienda a partir de septiembre de 1932. ${ }^{14}$ Por supuesto, en términos de escolarización, las escuelas graduadas eran muy rentables, pero los motivos no eran solamente económicos. La escuela graduada formaba parte del ideario político-pedagógico republicano, dado que se la asociaba con los aires renovadores que la revolución pedagógica amparaba: nuevas metodologías, espacios y prácticas que sólo eran factibles, en su sentido más refinado, en una graduada.

Sin embargo, esta asociación entre escuela renovadora y escuela graduada no había surgido de la nada. Se había consolidado entre la ilusión y los anhelos de modernidad que asistieron a la proclamación de nuevo régimen. Pero tenía una larga y secreta historia, en la cual no dejaban de

\footnotetext{
${ }_{11}$ Rodolfo Llopis, La revolución en la escuela: Dos años en la Dirección General de Primera Enseñanza (Madrid: Biblioteca Nueva, 2005), 23.

12 Véase Antonio Viñao Frago, Innovación pedagógica y racionalidad científica: La escuela graduada pública en España, 1898-1936 (Madrid: Akal, 1990), 23-24, así como, sobre las construcciones escolares durante la Segunda República, María del Pilar García Salmerón, Radiografía de las construcciones escolares públicas en España, 1922-1937 (Madrid: Ministerio de Educación y Formación Profesional, 2018), 259-272.

13 Gaceta de Madrid (14 mayo 1931): 717.

14 Gaceta de Madrid (18 septiembre 1932): 2026-2028.
} 
oírse los latidos del regeneracionismo de primeros de siglo, que hizo también de la escuela graduada una de sus banderas..$^{15}$

Todos los discursos regeneracionistas posteriores al 98, de las más diversas tendencias políticas, desarrollaron un discurso sobre la importancia de la educación para la renovación del país, afrontando la reforma pedagógica como un problema nacional. En este contexto, la escuela graduada encarnó la «nueva escuela» que necesitaba la «nueva España». Pero ¿qué se entendía por escuela graduada? Así lo resume María del Mar del Pozo:

La escuela graduada definía un tipo de centro educativo que constaba de varios grados o clases, en salas separadas y cada una de ellas con su respectivo docente, con una agrupación homogénea de alumnos según la edad, la capacidad intelectual o los intereses y unos programas de contenidos y tareas redactados bajos los principios de unidad y gradación progresiva, cuya aplicación era supervisada por una nueva figura docente, la del Director, quien estaba encargado de coordinar a todo el profesorado. La escuela graduada suponía, al menos en teoría, la construcción de edificios destinados a la instrucción primaria, con diversas aulas en las que nos niños pudieran agruparse según edades, con patios de recreo y salas para comedor, biblioteca, trabajos manuales, gimnasio, piscina, baños-duchas y cualquier otro tipo de actividades higiénicas, culturales o educativas. ${ }^{16}$

En consecuencia, la escuela graduada era concebida como la antítesis del modelo tradicional: la llamada escuela unitaria, donde un solo maestro se ocupaba, abandonado a sus fuerzas, de un grupo heterogéneo de alumnos confinados en un mismo espacio, a menudo inadecuado para la labor educativa. Contra estas escuelas-aula, la escuela graduada significaba un nuevo concepto de escuela pública que no sólo se ajustaba a las exigencias regeneracionistas, sino que comportaba una verdadera innovación en el sistema educativo: inauguraba nuevas dinámicas,

\footnotetext{
15 María del Mar del Pozo Andrés, Currículum e identidad nacional. Regeneracionismos, nacionalismos y escuela pública, 1890-1939 (Madrid: Biblioteca Nueva, 2000), 103-124.

16 Pozo, Currículum e identidad nacional, 104. Esta definición no deja lugar a dudas. Cuando hablamos de escuela graduada, no nos referimos a la graduación escolar, sino a un modelo de organización escolar completamente nuevo.
} 
usos de tiempos y espacios, de clasificación de alumnos, otra distribución de poder e inéditas posibilidades pedagógicas, materiales y sociales. En definitiva, una nueva cultura escolar. ${ }^{17}$

El advenimiento de la República supuso una continuidad con el optimismo pedagógico del regeneracionismo, hasta el punto de comprender la escuela primaria como una institución con una importantísima misión social. En esta, la graduada tendría un papel fundamental. Por motivos organizativos, espaciales, económicos y de personal, era la más capacitada para llevar a buen puerto los objetivos de socialización de la educación y la cultura, la acción social y los servicios complementarios que se esperaban de la escuela pública. En esta línea, entiende Antonio Viñao «la participación social en la escuela como estadio final del proceso de implantación de la escuela graduada». ${ }^{18}$ No sorprende, por tanto, que la escuela graduada fuese, al menos en un plano ideal, uno de los ejes del proyecto educativo republicano.

Ahora bien, la apuesta republicana por la escuela graduada se identifica con la apuesta por el director de graduada. Y esto se debe a que, bien comprendido el sistema graduado, el director es la graduada. En palabras de Viñao:

Lo usual entre los defensores de la escuela graduada es destacar la importancia, el papel clave a jugar por el director, y pedir, en consonancia, una formación y/o selección cuidadosa, específicamente atenta a su profesionalización. También existe, asimismo, un acuerdo general sobre el núcleo y esencia de la función directiva, aunque se exprese en diferentes términos: cuidar del conjunto y de la armonía, dar unidad de acción y criterios, de espíritu y métodos; en suma, coordinar y dirigir. ${ }^{19}$

Por consiguiente, apoyar al director de escuela graduada es apoyar la implantación efectiva de este sistema. Esto conlleva entender esta figura

\footnotetext{
17 Viñao, «La Dirección Escolar: un análisis genealógico-cultural», 379. De hecho, si la escuela graduada tuvo dificultades para implantarse en fechas anteriores a 1931, fue en gran medida debido a la resistencia que esta nueva cultura escolar despertó en parte del magisterio, acostumbrado al sistema unitario y reacio a la nueva distribución de poder.

18 Viñao, Innovación pedagógica y racionalidad científica, 80.

19 Viñao, Innovación pedagógica y racionalidad científica, 64.
} 
de un modo muy determinado: el maestro-director no sería un docente más a cargo de una serie de tareas más o menos burocráticas y mecánicas. Si el director de graduada jugaba un papel importante, éste no sería el de desempeñar las nuevas funciones organizativo-administrativas que requiere el funcionamiento de la escuela - los diversos registros de matrícula, alumnado y su desempeño en la escuela, planes económicos, distribución de material, etc. Por el contrario, la tarea esencial del director sería sustancialmente pedagógica: el director debía organizar, coordinar y liderar el conjunto de la graduada, dotar de unidad de acción a todas sus partes, crear un ambiente escolar propicio, definir la expansión social de la escuela mediante actividades extraescolares e instituciones circum y post-escolares, orientar y presidir las relaciones institucionales, etc. En definitiva, proyectar un ideal pedagógico que orientara armónicamente toda la obra de la institución.

Esta concepción de una «dirección fuerte» ${ }^{20}$ coincide con una serie de atribuciones específicas, distintas de las académicas —clasificación y elaboración de programas-, como la exención de la asignación de una sección a su cargo salvo suplencias, la supervisión y perfeccionamiento del profesorado, mediante lecciones-modelo o enmiendas personales y la introducción de nuevas técnicas e innovaciones pedagógicas.

La dirección de escuela graduada, así entendida, implicaba la irrupción de una figura de gran trascendencia para la organización y la práctica escolar. Al mismo tiempo, conllevaba una redistribución de poder y una reinterpretación de las relaciones entre los actores que participaban de la labor educativa: por un lado, la supervisión externa, que condicionaba el funcionamiento de los centros de una forma remota, quedaba reservada para la Inspección. Por el otro, surgía un espacio de poder, esta vez interno, que implicaba a toda la comunidad escolar y que quedaba bajo el control inmediato del maestro-director. Con esta nueva configuración de poder, surgían nuevas formas de interacción entre los implicados, insólitas para el modelo tradicional:

En el modelo de escuela-aula de un solo maestro, o escuela unitaria, las relaciones entre la inspección y los maestros eran directas, sin intermediarios. En una escuela graduada el inspector

\footnotetext{
${ }^{20}$ Viñao, «La Dirección Escolar: un análisis genealógico-cultural», 381.
} 
tenía que entendérselas, en primer lugar, con la dirección. Desde ésta, además, podían llevarse a cabo con más efectividad algunas de las funciones de control malamente ejercidas hasta entonces por la inspección. ${ }^{21}$

Podría incluso considerarse al maestro-director como «un inspector en la escuela», 22 cuya influencia ininterrumpida supliese las deficiencias de la propia Inspección que, por evidentes limitaciones, no podía conocer, con la precisión de la dirección, las aptitudes y necesidades del profesorado, del alumnado y del medio social en el que se desarrollaba la labor educativa. Este lugar privilegiado permite concebir la figura del director de graduada con suficiente entidad como para constituir por sí mismo la idea de un cuerpo muy selecto, de cuyo desarrollo dependía, en parte, la construcción de los discursos y las prácticas de la renovación pedagógica. Así lo considera, por ejemplo, Juan Mainer Baqué en su estudio sobre la genealogía de una didáctica de las ciencias sociales:

la creación de las graduadas propició la aparición de una figura que en algunas ocasiones, como tendremos ocasión de comprobar, fue clave como agente de control del desarrollo del currículo, divulgador de innovaciones y vocero-difusor de la importancia de las metodologías especiales en el saber y quehacer docentes: el director escolar que, al igual que los inspectores, además de sus funciones administrativas y gestoras, se granjeó poderes indiscutibles de liderazgo pedagógico e importantes tareas de elaboración académica, en un país que, recordémoslo, no vio nacer sus primeros cuestionarios para la Enseñanza Primaria hasta el año 1953, así como de supervisión y control del magisterio que trabajaba a sus órdenes. ${ }^{23}$

En conclusión, la dirección de graduada jugaba un papel más que relevante en el nuevo modelo pedagógico que la República pretendía extender. Por ello, es comprensible que los procesos de selección de este cuerpo especial de Direcciones de escuelas graduadas estuviesen presentes entre los

\footnotetext{
${ }^{21}$ Viñao, «La Dirección Escolar: un análisis genealógico-cultural», 383.

22 Viñao, Innovación pedagógica y racionalidad científica, 71.

23 Juan Mainer Baqué, La forja de un campo profesional. Pedagogía y Didáctica de las Ciencias Sociales en España, 1900-1970 (Madrid: Consejo Superior de Investigaciones Científicas, 2009), 53-54.
} 
desvelos del reformismo educativo republicano. Quizá los nuevos grupos escolares no fuesen tantos como era deseable, pero no cabía duda: la selección de los hombres y mujeres que debían ponerse al frente de estas escuelas constituía uno de los problemas más delicados para la renovación pedagógica que se deseaba emprender.

\section{El proceso de selección para las Direcciones de escuelas graduadas}

Una vez visto cómo encaja la escuela graduada en el ideario educativo republicano y la importancia de la dirección en dicho sistema, podemos hacernos cargo del proceso de selección diseñado para este grupo selecto de docentes. Ahora bien, ¿En qué consiste la particularidad de dicho proceso?

El nuevo proceso de selección de Direcciones de grandes Escuelas graduadas, dispuesto por Decreto de 1 de julio de 1932 (Gaceta del 5), regulaba la provisión de plazas vacantes y de nueva creación en la Enseñanza Primaria. Aunque las anunciadas profundas innovaciones respecto del nombramiento de las Direcciones de escuelas graduadas de seis o más secciones ${ }^{24}$ incluían también la descripción detallada de una serie de ejercicios, que tenían como finalidad evaluar cuidadosamente las aptitudes de los docentes, todo este proceso era precedido por la presentación de un «resumen de la labor profesional de los aspirantes con los documentos probatorios ${ }^{25}$ que cada uno de ellos considerase oportunos. Dicho resumen, sumado a una primera prueba escrita - un comentario e interpretación de un texto de pedagogía fundamental y de sus aplicaciones metodológicas-configuraba el proceso de preselección de los aspirantes que debían verificar el resto de los ejercicios. ${ }^{26}$

\footnotetext{
${ }^{24}$ Para las vacantes de escuelas graduadas de menor tamaño, este decreto preveía la elección del maestro-director por y entre los maestros de sección de la misma escuela. Sin embargo, esta medida sería rectificada en un prolijo decreto firmado el 14 de junio de 1935 (Gaceta del 19), donde se regulaba la provisión de estas plazas por concurso de traslado especial. Por regla general y a excepción de los egresados de la Sección de Pedagogía, tenían preferencia los aspirantes experimentados en Direcciones de graduadas de seis o más grados, así como los declarados aptos para estos puestos por concurso-oposición. En el caso de resultar plazas desiertas e independientemente del número de grados, la provisión se llevaría a cabo por concurso-oposición, conforme a la normativa que analizamos a continuación.

25 Gaceta de Madrid (5 Julio 1932): 120.

${ }^{26}$ Este primer ejercicio se realizaba en la capital de cada provincia y era evaluado por una comisión provincial. En la mayoría de los casos, dichos ejercicios se conservan junto a los expedientes que
} 
Por lo tanto, el delicado proceso de selección de este selecto grupo partía de una premisa: la exigencia a cada opositor de una práctica muy particular, que consistía en la construcción de un expediente, fundado en un relato sin pautas - una memoria de vida profesional- y suplementado con documentación que se considerase relevante, cuya diversidad dependía exclusivamente de la mayor o menor inventiva de su autor.

Pero ¿qué pretendía evaluarse mediante esa práctica más o menos creativa? Al reparar en lo escrito por Rodolfo Llopis en La revolución en la escuela, hallamos una clave para comprender la lógica interna de estos procesos de selección. En dicha obra, Llopis reflexiona en diversas ocasiones sobre los procesos de selección del personal de enseñanza primaria. La primera surge a propósito de las polémicas oposiciones de 1928. Se trata de un capítulo dedicado a la implantación de los cursillos de selección para el ingreso en el magisterio como congruente respuesta a una aspiración: "Había que acabar con las viejas oposiciones».27 Entre críticas al memorismo y automatismo del proceso tradicional, destaca el siguiente reproche: «Desaparecía la personalidad del opositor y quedaba sólo el ejercicio escrito. Era la deshumanización de las oposiciones». ${ }^{28}$

La reflexión sobre la personalidad del docente parece ser una preocupación primordial para Llopis. Cuando, más adelante, se ocupa de las oposiciones de cuerpos selectos, como el de la inspección, comienza la valoración de los nuevos procesos de selección, adaptados a la urgencia de proveer las plazas. Escribe entonces:

Por lo común, en los ejercicios tradicionales no se tenía en cuenta para nada los antecedentes profesionales de los aspirantes, la labor pedagógica por ellos realizada, sus publicaciones, las recompensas logradas en su carrera, etc. Ahora, por esta nueva reglamentación, el Tribunal ha de examinar detenidamente esos antecedentes, esa actuación anterior, que, en realidad, descubre

\footnotetext{
fueron aprobados y elevados a la comisión central donde se realizaban el resto de las pruebas. Esta documentación se encuentra depositada en el Archivo General de la Administración (AGA).

${ }^{27}$ Llopis, La revolución en la escuela, 119.

${ }_{28}^{28}$ Llopis, La revolución en la escuela, 112.
} 
la personalidad pedagógica del aspirante, y ya con esos valiosos elementos de juicio, debe realizar una primera selección de los

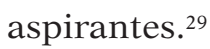

Podemos concluir que, mediante el nuevo procedimiento, se trataba deliberadamente de descubrir la personalidad profesional del docente bajo una exigencia narrativa. En otras palabras, se pretendía facilitar y proporcionar el contexto apropiado para la aparición del relato de una identidad profesional. La cuidadosa preselección consistía, por tanto, en la evaluación de la práctica de construcción de un expediente. Porque, como el propio Llopis había declarado en aquel artículo de Crisol el día de su toma de posesión, el problema más delicado era la utilización de los maestros en activo para la renovación pedagógica. Y la renovación del magisterio primario en aquellos años de urgencia dependería de la correcta selección de los grupos selectos. Estos puestos decisivos debían estar ocupados por genuinos maestros republicanos que, con su trabajo y entusiasmo, habían abonado el terreno en las décadas anteriores para hacer posible el advenimiento de la República.

Llegados a este punto, debemos preguntarnos: ¿qué entendemos por maestro republicano? María del Mar del Pozo ha reflexionado en diversos lugares acerca de esta cuestión:

Cuando los historiadores de la educación hablamos del colectivo de «maestros republicanos», creo que deberíamos especificar a qué grupo de maestros nos estamos refiriendo: ¿a la minoría de docentes que salieron de las aulas normalistas, formados en el plan de 1931, y que comenzaron a actuar profesionalmente por primera vez en 1935? ¿O a la gran mayoría de maestros que se habían educado con anterioridad en las Escuelas Normales, formados por los mismos profesores, aunque con un plan de estudios más tradicional, y que comenzaron a ejercer desde 1918? También deberíamos ser capaces de diferenciar entre aquellos docentes que se hicieron republicanos después del 14 de abril, bien por agradecimiento a una Republica que mejoró su dignidad profesional y social, bien por tener ya una arraigada mentalidad de funcionarios públicos, que seguían al Gobierno que les pagaba;

${ }^{29}$ Llopis, La revolución en la escuela, 179-180. Subrayado nuestro. 
y aquellos otros que vieron en la República la plasmación de unos ideales regeneracionistas en los que siempre habían creído y que se hicieron republicanos como culminación de una trayectoria vital comprometida con la idea de "salvar a España» a través de la educación. ${ }^{30}$

En este fragmento vemos la complejidad que encierra el concepto «maestro republicano» y una rica pluralidad de contextos y modos de construcción de aquellas identidades profesionales que el procedimiento que analizamos permite manifestar, o al menos escenificar. Sin embargo, trabajamos aquí con una acepción más de lo que puede considerarse el magisterio republicano, también propuesta por la misma autora y que nos sumerge en la problemática de la renovación pedagógica que estos expedientes-oposición permiten trabajar:

El aspecto que yo propongo como eje vertebrador de la identidad magisterial es el modo en el que interpretaron su práctica docente, sus autopercepciones como miembros de grupos innovadores y su posicionamiento personal en el continuum de la tradición/renovación pedagógica. Y es que para muchos maestros y maestras en los años treinta, el ser «republicano», independientemente de las implicaciones políticas e ideológicas que conllevase el término, significaba pertenecer a las vanguardias pedagógicas tan en boga y tan valoradas en aquella década. ${ }^{31}$

La cuidadosa selección de un magisterio republicano tendría mucho que ver, en este proceso de selección que analizamos, con la identificación y filiación de esa vanguardia pedagógica renovadora que se reconocía en el proceso de reforma republicana, y que ya se sentía partícipe de aquella callada revolución pedagógica que llevaba decenios gestándose en el país. El proceso de selección diseñado permitía la reivindicación

\footnotetext{
30 María del Mar del Pozo Andrés, «Los institucionistas y la política educativa española, 1898-1936: proyectos y realidades», en La Institución Libre de Enseñanza y Francisco Giner de los Ríos: Nuevas perspectivas. Vol. I. Reformismo liberal. La Institución Libre de Enseñanza y la política española, eds. Javier Moreno Luzón y Fernando Martínez López (Madrid: Publicaciones de la Residencia de Estudiantes, 2012), 275.

31 María del Mar del Pozo Andrés, «La construcción de la categoría "Maestra Republicana”: La tipología generacional como propuesta», en Las Maestras de la República, ed. Elena Sánchez de Madariaga (Madrid: Catarata, 2012), 239.
} 
de aquel reconocimiento, proporcionando un marco inmejorable ante tribunales de amplia competencia y autoridad pedagógica.

Asimismo, la estructura de estas oposiciones se adapta a otra idea formulada, una vez más, por María del Mar del Pozo, de la cual nos hacemos eco por haber inspirado muchas de estas páginas:

Aunque nunca se explicitó claramente, los nuevos responsables de la Administración republicana, que habían bebido en las fuentes institucionistas y orteguianas, y provenían en su gran mayoría de la generación de 1914, tenían siempre in mente la idea de fomentar la organización de minorías dirigentes en todos los ámbitos políticos y sociales. ¿Y qué mejor manera de crear ese club de selectos que propiciando el ingreso en los cuerpos de élite, esto es, en las Inspecciones y las Direcciones de graduadas, de los docentes mejor preparados, con mayor interés demostrado por la docencia y más implicados en la reforma?32

Los latidos de los institucionistas y orteguianos se perciben fácilmente en el proceso de selección que analizamos. El mismo Llopis se hizo cargo del viejo adagio institucionista: «El maestro es el alma de la escuela».33 Y son los buenos maestros los que debían distinguirse mediante el procedimiento de preselección analizado, formando una minoría selecta que debía liderar y dar forma a la masa magisterial, en el caso de la escuela graduada, desde la dirección. Eran estos los actores que debían dirigir, desde la práctica, la revolución pedagógica y social que se planteaba desde la escuela por la administración republicana.

En este sentido, creemos que dicho procedimiento de preselección de cuerpos docentes especiales favorecía intencionadamente la creación de lo que podríamos llamar provisionalmente una conciencia de élite pedagógica: mediante la exigencia de construcción del expediente que se exigía en el proceso preselectivo de las oposiciones a Direcciones de graduadas, se obligaba a una cierta reflexión acerca de la propia actividad docente, la cual podía cristalizar como un sentimiento de pertenencia a la vanguardia pedagógica del momento.

\footnotetext{
32 María del Mar del Pozo Andrés, Justa Freire o la pasión de educar. Biografía de una maestra atrapada en la historia de España, 1896-1965 (Barcelona: Octaedro, 2013), 80.

33 Llopis, La revolución en la escuela, 86.
} 
No obstante, aunque esta última propuesta se viese malograda, podemos establecer que la estructura de estas oposiciones permitió la configuración de un producto histórico muy singular y una ventana privilegiada para estudiar la construcción de las identidades profesionales de los docentes que decidieron acudir a ellas. Ahí radica el valor de estos expedientes-oposición como fuente histórico-educativa.

\section{LOS EXPEDIENTES-OPOSICIÓN A DIRECCIONES DE ESCUELAS GRADUADAS DE 1932}

\section{Antecedentes y descripción general}

Una vez precisado el contexto general de nuestra fuente y justificada la relevancia del cuerpo de directores y directoras de escuelas graduadas, nos propondremos analizar las características de estos expedientes-oposición, así como proponer el marco hermenéutico desde el cual pretendemos hacer fructífero nuestro estudio. Pero, antes de comenzar ese análisis, conviene reseñar los antecedentes de estas oposiciones para que podamos percibir la singularidad de la reglamentación del proceso de preselección diseñado por el gobierno republicano y su asociada práctica de construcción de expedientes.

Con anterioridad a 1926, las plazas de Direcciones de graduadas se proveían por concurso de traslado especial, donde se procedía automáticamente y con preferencia según el modo de ingreso, titulación, categoría, experiencia, etc. ${ }^{34}$ Esto sería modificado por el Real Decreto de 23 de agosto de 1926 (Gaceta del 28), que disponía la provisión de las Direcciones de los grandes Grupos Escolares — seis o más grados- y parte de su profesorado por concurso-oposición «entre Maestros nacionales que reúnan las condiciones de edad, servicios y cultura especiales que determine en cada caso la Real orden de su convocatoria, que designará además el número, clase y naturaleza de los ejercicios que han de realizar los aspirantes». ${ }^{35} \mathrm{El}$ decreto no especificaba, por tanto, la naturaleza del procedimiento.

\footnotetext{
${ }^{34}$ Gaceta de Madrid (25 de Julio 1918): 250, y Gaceta de Madrid (19 mayo 1923): 686.

35 Gaceta de Madrid (28 agosto 1926): 1239.
} 
Poco tiempo después, por Real Orden de 17 de septiembre de 1926 (Gaceta del 19), se convocó un concurso-oposición para adjudicar Direcciones de Grupos Escolares de Madrid. Entre sus disposiciones, se anunciaba un proceso de preselección entre todos los que cumpliesen los requisitos iniciales —límite de edad, titulación y modo de ingreso- que consistía en la entrega de:

trabajos escritos de su puño y letra, sin fecha ni firma, acerca de los siguientes puntos: a) Orientaciones pedagógicas respecto de la organización y régimen que debe seguirse, a su juicio, en la enseñanza de las Escuelas graduadas. b) Materias propias de los cursos complementarios y organización de las mismas, en armonía con las artes y oficios, industria y comercio, de Madrid, para facilitar medios de vida a los alumnos. ${ }^{36}$

Se trataba, por tanto, de memorias técnicas pautadas con un itinerario estricto, a partir de las cuales se realizaba un proceso eliminatorio previo al ejercicio. También en las convocadas en 1928 para la provisión de Direcciones de escuelas graduadas se siguió un diseño similar. Según la convocatoria del 20 de agosto de 1928 (Gaceta del 22), se requería de los aspirantes:

una Memoria, que comprenderá tres partes: primera, organización de la enseñanza de adultos y de los estudios complementarios que estime precisos, atendiendo a las ocupaciones y trabajos propios de la comarca o lugar donde esté la Escuela, y los que juzguen convenientes para encauzar y aprovechar las vacaciones y aptitudes de algunos alumnos para estudios superiores, segunda, exposición detallada y documentada de los trabajos que sobre esos extremos y con esas orientaciones haya realizado el aspirante, y tercera, ordenación de la enseñanza del dibujo en seis secciones [...]. ${ }^{37}$

De nuevo, se trataba de una memoria pautada que delimitaba explícitamente la orientación del escrito, sirviendo su evaluación para la admisión a la posterior verificación de los ejercicios. Este modelo de memorias se extinguió junto con esas mismas oposiciones, que no fueron

\footnotetext{
36 Gaceta de Madrid (19 septiembre 1926): 1674. Subrayado nuestro.

37 Gaceta de Madrid (22 agosto 1928): 1036. Subrayado nuestro.
} 
resueltas hasta bien entrado el año 1931 y por liquidación del nuevo gobierno. ${ }^{38}$

El 3 de diciembre de 1932, el Ministerio republicano publicó la convocatoria del concurso-oposición para proveer 50 plazas de Directores y 50 de Directoras de Escuelas graduadas de seis o más secciones. ${ }^{39}$ Sería el primero y único celebrado en este periodo, y el único bajo las directrices marcadas por el Decreto del 1 de julio de 1932 que hemos analizado más arriba. A él se presentaron más de 500 aspirantes procedentes de todas las provincias del país.

Como ya hemos anticipado, a todos los aspirantes se les exigía para formar expediente, además de una serie de requisitos mínimos —fundamentalmente cinco años de servicios en propiedad y, por tanto, cierta experiencia docente-, un resumen de la labor profesional con los documentos adjuntos que se considerasen oportunos para avalarla. Esta composición era requisito indispensable, puesto que, conforme al espíritu del decreto, era necesaria para evaluar la preselección de aspirantes por parte de las comisiones provinciales encargadas de esta fase inicial.

El cambio que advertimos en esta nueva regulación respecto de sus precedentes es precisamente una omisión: se exigía una memoria, pero este requerimiento carecía por completo de pauta alguna. Tampoco había concreción respecto al número y carácter de la documentación que podía ser utilizada para avalar las memorias. En definitiva, la falta de precisión que marcaba la normativa a este respecto dejaba un margen para cierta libertad y creatividad al construir estos expedientes. Se abría, por tanto, un espacio de decisión que cada opositor podía explotar, bajo su responsabilidad, al representarse ante el tribunal. Al mismo tiempo, esas decisiones obligaban a una cierta auto-reflexión y configuración de esa misma representación. Nos encontramos, por ende, ante una fuente con características únicas para estudiar la construcción, representación y publicación de las identidades profesionales de un segmento clave del magisterio de la República.

\footnotetext{
${ }_{38}$ Gaceta de Madrid (3 julio 1931): 78-79.

39 Gaceta de Madrid (3 diciembre 1932): 1609-1610.
} 


\section{Los expedientes-oposición como archivos de vida}

La especial estructura de esta fuente, concretada en la peculiar exigencia de una composición de estos expedientes, nos incita a plantear un marco teórico determinado que nos permite interpretar la variedad de materiales que proporcionan dichos expedientes.

Aludíamos antes a las bases reguladoras de la oposición que reservaban a los opositores un cierto margen para componer sus expedientes. Este espacio de indeterminación posibilitaba una pluralidad de estrategias: desde la variedad de estilos de redacción, presentación, extensión y temáticas de las memorias, hasta la diversidad de documentos que podían acompañarlas — certificados oficiales; recomendaciones; informes; publicaciones; recortes de prensa; trabajos, cuadernos y diarios escolares; fotografías, etc.- - Esta patente libertad de composición nos insta a concebir la construcción de los expedientes-oposición como una práctica de archivo de vida: una selección significativa de fragmentos documentales mediante los cuales se representa un relato pretendidamente coherente de la vida e identidad profesional de quien la realiza. Mediante esta práctica, cada aspirante produce un relato de sí mismo, que trata de apropiarse para sí y ante el tribunal que debe juzgarlo.

Para justificar nuestro uso de esta noción de archivo de vida atendemos a la definición que propone Philippe Artières, ${ }^{40}$ y que él mismo asume como marco teórico y herramienta metodológica para trabajar fuentes primarias. Artières establece tres trazos comunes que aparecen en las prácticas de archivo de vida: a) un distanciamiento respecto de sí de quien archiva su vida, b) un deseo de testimonio implícito en esta práctica, y c) un acto de resistencia e interpelación directa al posible receptor. Estos tres elementos pueden reconocerse en la práctica de archivo de vida que los aspirantes efectúan al construir su expediente.

En efecto, archivar la vida supone, en primer término, un distanciamiento respecto de sí de quien realiza la acción. En tanto que surge de una imposición social, implica una selección que conlleva una reflexión sobre la vida que se va a representar y sobre el relato que se va a narrar. Este relato, a su vez, se sabe como uno de los posibles - efectivamente,

\footnotetext{
40 Philippe Artières, «Arquivar a Própia Vida», Revista de Estudos Históricos 11, no. 21 (1998): 9-34.
} 
será valorado por el tribunal con el beneficio de la duda-, por lo que se deben ofrecer pruebas fehacientes: una selección de eventos y documentos significativos. La narración se articula mediante un pacto con la realidad y, por tanto, una unidad narrativa más o menos coherente que disimula las fisuras y que omite o destaca elementos al servicio de un objetivo: la representación de una identidad profesional.

Vinculada a la unidad del relato que origina el archivo, surge un afán de testimonio. El archivo de vida pretende atestiguar una trayectoria personal que, si bien es testimonio de los logros, también lo es de las dificultades. Pronto, esa trayectoria converge con la justificación de un modo de proceder ampliable a un colectivo y con una interpretación sobre lo que deben ser el maestro, la escuela, la enseñanza, etc. A menudo, ese afán testimonial oculta, tras sus decisiones, la construcción de un ideal pedagógico que participa de algún modo en la renovación pedagógica de la que se siente testigo.

La construcción del ideal pedagógico reserva también la posibilidad de una crítica de las realidades que se oponen a él. Cada relato tiene la posibilidad de dar voz a una resistencia en el marco institucional de la oposición. Cada gesto crítico o complaciente podría ser estudiado para entender mejor la construcción de los discursos y la percepción de las prácticas pedagógicas narradas sin perder de vista sus asunciones y omisiones. El archivo se erige como dispositivo de resistencia en un doble sentido: el de una denuncia pública y el de la escenificación de una identidad.

Todo este proceso se da bajo el presupuesto de la función pública del archivo: archivar la propia vida es de algún modo publicarla, exponerla y defenderla con y ante los otros, bajo unas condiciones de producción definidas. Es, por tanto, construir una imagen que ha de ser validada, negociada o impugnada. Cada decisión, independientemente de su grado de veracidad, es significativa y, lejos de reproducir una identidad preconcebida, la produce, anticipando su contexto de producción y la autopercepción del productor.

En última instancia, la concepción de la unidad de cada expediente como un archivo de vida permite comprenderlos en toda su complejidad, sin menospreciar la variedad de materiales que pueden presentar; como 
una toma significativa de decisiones por parte de los opositores, que no está exenta de las tensiones que determinan la construcción, apropiación y presentación pública de una identidad profesional y de un discurso pedagógico, tanto ante el tribunal de oposición como ante sí mismos. Dicho marco es óptimo para estudiar cómo se construyen esas identidades profesionales, y evaluar la posible producción de una conciencia de élite pedagógica en aquéllos que están obligados a narrar y archivar su vida.

\section{UN ESTUDIO DE CASO: EL EXPEDIENTE-OPOSICIÓN A DIRECCIONES DE GRADUADAS DE MARÍA SÁNCHEZ ARBÓS}

Una vez hemos definido el marco interpretativo según el cual podemos hacernos cargo de estos expedientes, trataremos de hacerlo operativo mediante la lectura de uno de ellos. A continuación, procederemos a analizar el expediente-oposición de María Sánchez Arbós, una de las aspirantes que, viéndose atraída por este proceso de selección, concurrió en la provincia de Madrid.

Aunque su expediente-oposición no es de los más variados respecto del tipo de documentación que adjunta —incluyendo sólo el resumen de su labor profesional y una serie de certificados—, ${ }^{41}$ sí lo estimamos como un ejemplo funcional del modelo interpretativo que acabamos de proponer. Por otra parte, Sánchez Arbós constituye una de las figuras más conocidas y representativas del periodo histórico que estudiamos. Cabe decir que también se posicionó como número uno en las listas de relación de mérito resultantes de la oposición que nos ocupa, tanto en la provincial como en la nacional. Ahora bien, lo que más nos atrae de su expediente es que nos permite reconocer esa práctica de archivo de vida que hemos estado analizando. Su archivo de vida es significativo por el discurso que representa y por la selección documental que lo avala. Su construcción revela, sin lugar a dudas, una identidad profesional. Por último, también nos permite ilustrar las posibilidades y estrategias que

\footnotetext{
${ }^{41}$ Excluimos de nuestro análisis el ejercicio escrito, también depositado en su expediente, por la constricción a la libertad de composición que implica el tema a desarrollar, sacado en suerte entre los varios propuestos por el tribunal. El texto objeto de comentario fue «La risa de los niños» de D. Francisco Giner de los Ríos y, aunque la respuesta de Arbós sea original y de indudable interés, consideramos que excede el marco hermenéutico que nos hemos trazado.
} 
proporciona este marco interpretativo al complementar la lectura del archivo de vida institucional con otro modelo de archivo de vida: el archivo autobiográfico. Proponemos aquí una lectura comparada de dos fuentes: el expediente-oposición de 1932 y Mi Diario, publicado por Sánchez Arbós en 1961.42

A propósito de este Diario, conviene hacer algunas precisiones. Por motivos contextuales -el ambiente político de la España del momento, donde Arbós residía-, fue una obra editada y autopublicada en México, con una tirada muy reducida de apenas 100 ejemplares y destinada en su integridad al círculo íntimo de la autora. ${ }^{43}$ El contenido del Diario publicado se hizo a partir de una colección de notas que dicha maestra había ido recogiendo en un cuaderno durante su vida profesional, conformando «una selección relativamente breve y recortada de esas notas, realizada libremente por su autora». ${ }^{44}$ Esta selección constituye el núcleo del Diario, que se comprende como una transcripción de fragmen$\operatorname{tos}^{45}$ que abarcan desde 1918 hasta el año de su retiro, en 1959. A este conjunto de notas se suma una segunda parte, consistente en una serie de artículos que la propia Sánchez Arbós había publicado en el Boletín de la Institución Libre de Enseñanza, entre los años 1932 y 1936. Mi Diario fue publicado de nuevo por el Departamento de Educación y Cultura del Gobierno de Aragón en 1999 — en una versión parcial que no incluía la segunda parte—, con una reedición en 2006 — esta vez íntegra—, siendo esta última la edición que utilizaremos para nuestra lectura comparada. No utilizaremos la edición de textos de María Sánchez Arbós publicada en 2007 por Biblioteca Nueva, ${ }^{46}$ entre los que se incluyen textos inéditos del Diario, por no formar parte de la selección original ejecutada

\footnotetext{
42 Sobre el uso de las autobiografías y diarios y, en concreto, los firmados por docentes como fuente histórico-educativa, véase: Antonio Viñao Frago, «Las autobiografías, memorias y diarios como fuente histórico-educativa: tipología y usos», Sarmiento 3 (1999): 223-253.

43 Véase Víctor Manuel Juan Borroy, «La mirada de una maestra» en Mi Diario, ed. María Sánchez Arbós (Zaragoza: Gobierno de Aragón y Caja Inmaculada, 2006), 15-17.

${ }_{44}$ Elvira Ontañón, «Prólogo», en Mi Diario, ed. María Sánchez Arbós (Zaragoza: Gobierno de Aragón y Caja Inmaculada, 2006), 21.

${ }^{45}$ Así lo hace constar la propia Sánchez Arbós en el breve proemio que antecede al primer registro del Diario: «Desde entonces fui anotando mis recuerdos en el cuaderno que, a través de no pocas vicisitudes, he conservado hasta hoy, y algunas de cuyas páginas voy a transcribir». María Sánchez Arbós, Mi Diario (Zaragoza: Gobierno de Aragón y Caja Inmaculada, 2006), 69.
}

46 Véase María Sánchez Arbós, Una escuela soñada (Madrid: Biblioteca Nueva, 2007). 
por María Sánchez Arbós y por abarcar un periodo de fechas -19331936- que exceden a los del expediente-oposición.

Teniendo en cuenta estos detalles a propósito del Diario, podemos afirmar que ambos archivos de vida tienen por objeto representar la propia vida, pero que cada uno de ellos se realiza en condiciones muy diferenciadas. Atendiendo a sus diversos contextos e intenciones - explicitas o implícitas-, podremos contrastar el nivel de coherencia, cada énfasis u omisión, un recuerdo u olvido, etc. abriendo nuevos cuestionamientos y, en definitiva, asistiendo y problematizando el complejo proceso de la construcción y reconstrucción de una identidad profesional.

Comenzaremos nuestro análisis del expediente-oposición por el relato que constituye su práctica de archivo y que se basa concretamente en el resumen de su vida profesional. El modo escogido por Sánchez Arbós para representarse es una memoria, en este caso manuscrita, en la que narra una breve reseña biográfica de su labor como docente. Titulada $\mathrm{Mi}$ labor profesional, consiste en una descripción por etapas de su trayectoria profesional desde que terminase sus estudios en la Escuela Normal de Zaragoza.

Las primeras líneas están dedicadas al inicio de su carrera: Sánchez Arbós nos cuenta en primera persona cómo, una vez acabados sus estudios de Maestra Superior hacia 1908 en Zaragoza, obtiene su primer destino interino: una sección de párvulos en aquel mismo municipio. Declara haber ocupado ese cargo apenas unos meses, al considerar necesario ampliar sus estudios: «Pocos meses estuve en ella porque preferí ampliar mi cultura y hacerme Bachiller, como lo hice, en dos convocatorias».47

Con el nuevo título en su haber se desplaza con su familia a Barcelona, donde desempeña durante unos meses una sección en las Escuelas del Bosque. Deja este nuevo puesto para tomar parte en las primeras oposiciones que se hacían por un nuevo plan. Tiene la suerte de alcanzar buen número, por lo que obtiene su primera escuela en propiedad: una sección en la Escuela Graduada de San Ildefonso en Segovia. Se trataba de su ingreso en el Magisterio, evento que adquiere cierto apasionamiento en

\footnotetext{
47 María Sánchez Arbós, «Mi labor profesional», 30 de enero de 1933, educación, 32/10720, Archivo General de la Administración (AGA).
} 
el relato: «entré a cumplir mi cometido con el mayor entusiasmo y los mejores deseos».48

Esta primera escuela, servida de 1913 a 1915, es el escenario de una esperanza inicial de renovar la escuela nacional, pero también de la constatación de un primer fracaso: «Con el optimismo propio de los pocos años, yo creí que podría cambiar la Escuela a mi antojo y que realizaría una obra muy superior a la de las escuelas que yo conocía. Confieso que fracasé». ${ }^{49}$ Ese fracaso, muy oportunamente, tiene que ver con un modelo anticuado de promoción en las escuelas graduadas, según el cual se dejaba la dirección en manos de la experiencia, que aquí viene asociada a la senectud de un sistema caduco: «La Escuela a la que yo fui tan ilusionada acababa de graduarse con la funesta tradición de dejar la Dirección a la antigüedad y aquella Señora ya vieja, tomó por descabellados mis planes».50 La renovación pedagógica toma por momentos un cariz generacional: la juventud y la vejez escenifican una arquetípica pugna. Pero ¿qué tipo de censura u oposición representaba aquella vetusta dirección? Si atendemos, por primera vez, a la lectura comparada del Diario, encontramos una secuencia de este desengaño durante la tentativa de una clase al aire libre:

$\mathrm{Al}$ abrir la puerta de salida, me sorprendió la seria figura de la Directora que daba la orden de que todo el mundo volviese a su sitio, ya que ella no consideraba aquello pedagógico ni había sido consultada. Tuvimos que obedecer. A algunas niñas y a mí nos asomaron las lágrimas. Por primera vez se me ocurrió pensar que la escuela no era mía y que mientras estuviera allí, no podría hacer más que obedecer órdenes superiores. ${ }^{51}$

La memoria finaliza esta etapa con una cierta resignación ante el estado de cosas: "después de dos años de inútil lucha, me vi obligada a trasladarme a la Escuela de Almorox»,52 y un lamento: "Ningún comprobante puedo ofrecer de aquellos mis primeros ensayos. La Directora

\footnotetext{
${ }^{48}$ Sánchez, «Mi labor profesional».

49 Sánchez, «Mi labor profesional». Subrayado nuestro.

${ }^{50}$ Sánchez, «Mi labor profesional». Subrayado nuestro.

${ }^{51}$ Sánchez, Mi Diario, 68. Subrayado nuestro.

${ }^{52}$ Sánchez, «Mi labor profesional».
} 
deshacía cuanto yo intentaba y el Inspector ni lo conocí ni apareció nunca por mi Escuela».53

La obtención mediante permuta de una nueva escuela graduada en Toledo supone un nuevo intento de renovación de la escuela ante una nueva dirección. Sin embargo, la nueva situación tampoco se presenta favorable: «Ocupaba la Dirección interinamente una muchacha joven, hija del pueblo a quien las conveniencias sociales no le permitían variar por nada la desastrosa tradición». ${ }^{44}$ En esta ocasión, la juventud de la directora tampoco permite sortear el fracaso. La escuela estaba constreñida por su ambiente y el atavismo hacía presa a la inexperiencia. La conclusión es clara: «en vista de esto y antes de luchar como en S. Idelfonso, me vine a Madrid y tomé parte de los ejercicios de ingreso para la Escuela Superior del Magisterio y alcancé el $\mathrm{n}^{\circ} 3$ de aquella convocatoria del año 1916».55

De 1916 a 1918, la memoria describe un segundo periodo de formación de gran efervescencia. El paso por la Escuela Superior de Magisterio es simultaneado con estudios universitarios, obteniendo el grado Normal, la Licenciatura en Filosofía y Letras y, poco después, el ingreso en el Doctorado. También comienzan las relaciones con entornos institucionistas, mediante la concesión de una Beca en la Residencia de Señoritas durante el primer curso. El último año en la Escuela coincide con la creación del Instituto-Escuela, donde realiza las prácticas y se ocupa de la Sección primaria entre 1918 y 1920. Aparecen citados los nombres de María Goyri y María de Maeztu. De esta última precipita comentarios sobre el trabajo realizado bajo su mando: «La Srta. de Maeztu me dio amplia libertad de hacer y organizar y entonces llevé a cabo mis ensueños de San Idelfonso y mil veces pensé con lástima en aquellas pequeñas que no tuvieron la fortuna de disfrutar de una escuela tolerante y afectuosa». ${ }^{56}$ Estos elogios revelan un ambiente grato en el que su labor como maestra parece desenvolverse sin problemas. Sin embargo, si atendemos a esta misma etapa en el Diario, nos percatamos también de sentimientos encontrados, de las tristezas entre las alegrías:

\footnotetext{
53 Sánchez, «Mi labor profesional». Subrayado nuestro.

54 Sánchez, «Mi labor profesional». Subrayado nuestro.

55 Sánchez, «Mi labor profesional».

56 Sánchez, «Mi labor profesional». Subrayado nuestro.
} 
Me gustaría que las personas que están al frente de todo esto se fijaran un poco en mi trabajo y en lo que consigo con los niños, para que, como maestras mías, aprobaran mi trabajo y me alentaran en el esfuerzo. Los únicos que los aprecian son los niños, y, aunque los quiero tantísimo, necesitaría mi esfuerzo otros jueces más capacitados. ${ }^{57}$

En esta confesada queja se advierte el peso de un aislamiento, de una falta de trabajo en equipo, quizá de una falta de organización. Cinco registros después, anota en el Diario la noticia de su nombramiento como profesora en la Escuela Normal de La Laguna, del cual dice: «No me ha producido ninguna ilusión. He vuelto a clase como avergonzada de cambiar mi labor». ${ }^{58}$ La misma nota concluye: «Falta mucho que organizar en la escuela primaria, y no pierdo la esperanza de ser útil algún día».59

Este nombramiento, que da comienzo a una nueva etapa, irrumpe en la memoria de súbito cuando finalizan las prácticas en el Instituto-Escuela. Pero la interpretación parece tener aquí un matiz diferente: «En junio de 1920, fui nombrada Profesora de Lengua de la Escuela Normal de Canarias. Dejé con pena mi sección del Instituto, pero creí que la misión de formar maestras era todavía más interesante que la de los 30 niños que dejaba». ${ }^{60} \mathrm{Su}$ intento de renovar la escuela incorpora un nuevo objetivo: la formación del magisterio. Pero tampoco esta vez parece ayudar la nueva tesitura: «Aquella Normal estaba anticuada, el retraso con todo era enorme, y el desorden muy marcado».61 Una cierta desilusión subraya de nuevo la trama de la organización de las instituciones educativas que ya se anunciaba en el Diario a propósito de su nuevo destino: «Mi labor es en parte la formación de maestras, pero es labor que ha de hacerse en común». ${ }^{2}$ Sin embargo, esta deficiencia sería suplida parcialmente por «una Directora muy cumplidora de su deber y muy entusiasta

\footnotetext{
57 Sánchez, Mi Diario, 83. Subrayado nuestro.

58 Sánchez, Mi Diario, 86.

59 Sánchez, Mi Diario, 86.

60 Sánchez, «Mi labor profesional». Subrayado nuestro.

${ }^{61}$ Sánchez, «Mi labor profesional».

62 Sánchez, Mi Diario, 88.
} 
de las que cumplían», ${ }^{63}$ gracias a la cual confiesa una buena labor tanto dentro como fuera de la escuela y confirmada con un gran número de alumnas aprobadas en oposiciones de ingreso al magisterio. También manifiesta ocupar puestos de auxiliar universitaria y ayudante de Instituto durante este periodo. Esta etapa finalizará con un traslado a la península: la Escuela Normal de Huesca. La motivación de este cambio puede ilustrarse con otra sentencia de su Diario, escrita meses antes de su marcha: «Los que no tenemos aquí más raíces que el destino, no sabemos mantener un entusiasmo que ni es pagado, ni es reconocido». 64

La vuelta a su ciudad natal en 1926 se acentúa en la memoria con nuevos deseos de trabajar. Sin embargo, este traslado no viene acompañado de una esperada mejora de condiciones laborales. Más bien, al contrario, aparecen nuevos problemas: «Cuestiones de orden familiar y religioso, así como la oposición a mi labor del Obispo de aquella Diócesis, me obligaron a pedir la excedencia para evitar mayores perjuicios» .65 De este modo, el nuevo tramo acaba en 1929 con cierta sensación de fracaso y de un fin de ciclo. Acerca de los problemas hallados en Huesca, su Diario constata: «Si yo pudiera hacer buenas maestras, no escatimaría esfuerzo, pero la Escuela Normal no es obra de una profesora; somos un grupo de ellas que deberíamos compenetrarnos en la labor y preocuparnos para una obra común en beneficio de las futuras maestras».66 Aislamiento y falta de trabajo en grupo vuelven a enunciarse. Meses más tarde queda consignado en el mismo Diario: «Una idea que sin cesar me bulle en la cabeza, acabará por ganar la partida. Tal idea es abandonar las Escuelas Normales para volver a trabajar en Escuelas primarias».67 La reforma de la escuela desde arriba se ha malogrado.

Seguidamente, la memoria recoge el periodo de excedencia, donde la principal convicción es volver a la Enseñanza Primaria con intención de opositar de nuevo a Escuelas Nacionales. Lo hará en las de 1928, abarcando

\footnotetext{
${ }^{63}$ Sánchez, «Mi labor profesional».

${ }^{64}$ Sánchez, Mi Diario, 100.

${ }^{65}$ Sánchez, «Mi labor profesional».

${ }^{66}$ Sánchez, Mi Diario, 103. Subrayado nuestro.

${ }_{67}$ Sánchez, Mi Diario, 104.
} 
esta etapa el largo periodo de su resolución. Durante este tiempo, Sánchez Arbós describe en la memoria su desplazamiento a Madrid:

[...] dispuesta a trabajar entre los que me conocían. Entré de nuevo en el Instituto-Escuela. Me encargué de las clases de la Lengua en la Sección Secundaria y volví de profesora a la Sección primaria de la Institución Libre de Enseñanza cuyo acogimiento se me había prestado ya en las andanzas de mi primera Escuela. ${ }^{68}$

También consigna su colaboración en la publicación del Romancero Español, junto con los Sres. Menéndez Pidal en el Centro de Estudios Históricos. En definitiva, la vuelta a Madrid es sinónimo de afiliación a la vanguardia educativa, que se identifica con la Institución Libre de Enseñanza —en adelante ILE. Este periodo acaba con la resolución de las oposiciones. Sánchez Arbós había obtenido plaza como maestra de sección en el madrileño Grupo Escolar «Menéndez Pelayo».

La vuelta a la enseñanza primaria se presenta como un nuevo comienzo: «He vuelto pues a la Escuela después de 14 años. No sé si por lo que he rodado, o porque mis hijos me hacen querer más a los hijos de todos, lo cierto es que he vuelto a la Escuela con más entusiasmo aún del que llevé el año 1913».69 También la escuela ha cambiado en este tiempo: «Esta Escuela española, ha ganado mucho, en instalación, en refinamientos, en comodidades». ${ }^{70}$ La labor se realiza bajo la dirección de una directora que es definida como tolerante y abierta a las innovaciones. Sin embargo, algo falla todavía. La escuela graduada no es aun lo que debe ser, como deja ver el colofón de la memoria: «Tiene sin embargo la escuela, un vacío grande que llenar, una intensa labor por hacer, y una obra social fundamentalísima que es la única que puede formar un mañana más deseable, más completo y más humano». ${ }^{71}$ Esta terminación, así presentada, abre una pregunta comprensible: si la escuela no es aún como debe ser, ¿cómo debe ser? Y más aún ¿quién está en posición de llevarla a cabo? ¿Cuáles son sus avales?

\footnotetext{
${ }^{68}$ Sánchez, «Mi labor profesional».

${ }^{69}$ Sánchez, «Mi labor profesional».

${ }^{70}$ Sánchez, «Mi labor profesional».

${ }^{71}$ Sánchez, «Mi labor profesional».
} 
A estas últimas palabras se suman una serie de documentos probatorios que Sánchez Arbós consideró pertinentes para respaldar su memoria. Son todos certificados, pero basta con observar que, de los ocho entregados, cuatro proceden de la esfera de la ILE, siendo el más valioso el firmado por el mismo Manuel Bartolomé Cossío, donde, en tono elogioso, describe su «ingenio pedagógico», su «sólida formación» y otras cualidades muy en consonancia con «el vasto campo y laboriosas funciones que acompañan siempre a todo complicado organismo docente». ${ }^{72}$

Como resultado de nuestro análisis, podemos dar una visión de conjunto del archivo completo y de la identidad pedagógica que representa. En él, Sánchez Arbós se ha cuidado de identificarse como parte de aquella vanguardia pedagógica que trató de transformar la escuela. Y lo ha hecho percibiéndose como una heredera espiritual de la ILE. Asumió la renovación pedagógica desde sus primeras escuelas e intentó transformar la escuela desde abajo, desde la práctica. Su falta de formación le hizo tropezar y la llevó a perfeccionar su instrucción. Poco después, llegó a una nueva convicción: para la transformación de la escuela, sería necesaria la transformación desde arriba, la formación del magisterio — «Dadme el maestro», diría Giner de los Ríos. Pero es a partir de un nuevo tropiezo y al final de este proceso cuando comprende la necesidad de una vuelta a la enseñanza primaria, con una secreta certidumbre: sólo desde la dirección de una gran graduada podría realizarse la escuela soñada, actuando directamente como maestra-directora sobre maestros, alumnos y sobre la sociedad circundante. La dirección de un grupo escolar y el aval de su propia trayectoria representan la oportunidad para organizar, desarrollar y transformar la escuela pública desde un ideal de escuela graduada y con plena capacidad de acción. Este discurso sería reconocido por la comisión calificadora madrileña ${ }^{73}$ y explicaría el descargo que Sánchez Arbós supone al construir su expediente respecto de cuestiones metodológicas concretas y descripciones pormenorizadas de su práctica escolar, muy presentes en los relatos de otros opositores.

\footnotetext{
72 «Certificado del Rector de la Institución Libre de Enseñanza», 8 de diciembre de 1932, educación, 32/10720, Archivo General de la Administración (AGA).

${ }^{73}$ En las actas de evaluación razonada aparece, entre otros motivos, el siguiente: «formada al lado de los espíritus más levantados y selectos en ciencia y educación, con informes terminantes sobre su valor profesional y personal». Véase «Actas de la Comisión Calificadora de Madrid», 16 marzo de 1933, educación, 32/10717, Archivo General de la Administración (AGA).
} 
Ahora bien, sabiendo que la labor al frente de la dirección del Grupo Escolar «Francisco Giner» sería el cargo más importante de su carrera, ${ }^{74}$ cabe preguntarse por la mención que se hace en el Diario acerca de las oposiciones por las que obtuvo la plaza. Encontramos esta anotación fechada a día 3 de febrero de 1933:

El primer ejercicio de las oposiciones a Direcciones de Grupos escolares ya se verificó. Fue un escrito, en el que había que hacer un comentario sobre «La Risa de los niños». Se podía elegir entre ese tema y otro de metodología que ni recuerdo [...] En el ejercicio práctico, que se hizo a continuación, elegí (estaba permitido) un grupo de niños de cuatro y cinco años a los que pretendí enseñar a leer en aquella media hora [...] Hoy, cuando han publicado la lista de calificación, me ha satisfecho verme en el primer lugar. ${ }^{75}$

Este apresurado relato resulta sorprendente si tenemos en cuenta que la primera lista de calificación no sería publicada hasta el 7 de abril (Gaceta del 8), verificándose el segundo ejercicio de metodología —obligado, y no opcional- el 21 del mismo mes, y el ejercicio práctico, bien entrado el mes de junio. La lista definitiva que debió satisfacer a Sánchez Arbós se hizo esperar hasta la Gaceta del 15 de agosto. El desconcierto ante el solapamiento de fechas es completo cuando observamos que la entrada del Diario se habría anticipado 17 días a la fecha efectiva, 20 de febrero, del primer ejercicio que abre la narración. ${ }^{76}$

El evidente proceso de reescritura que afecta al Diario compromete su integridad como diario profesional, pero deja intacto su valor como archivo autobiográfico. Por supuesto, no es la única incoherencia u omisión que puede apreciarse en una cuidadosa lectura comparada. Su estancia en Zaragoza, su desempeño en las Escuelas del Bosque, la dudosa ancianidad de la directora de San Ildefonso, ${ }^{77}$ la ausencia de

\footnotetext{
${ }^{74}$ Basta comparar el número de entradas que se dedican a este desempeño durante los solo tres años que estuvo activo, y que constituyen el núcleo del Diario.

75 Sánchez, Mi Diario, 121-122. Subrayado nuestro.

${ }^{76}$ Respecto a los fragmentos inéditos publicados en 2007, a los cuales nos hemos referido antes, cabe anotar que en ninguno de ellos aparece mención alguna al proceso de oposición o al resultado del mismo. Véase: Sánchez, Una escuela soñada, 67-132.

${ }^{77}$ El Diario le atribuye 40 años. Es un índice de senectud un tanto arriesgado, teniendo en cuenta que Sánchez Arbós escribía la memoria con 42.
} 
énfasis en la formación del magisterio, la misteriosa desaparición -o aparición, según se mire- del Obispo oscense, la omisión del encargo de Eladio García - Inspector-Jefe y presente en el primer Tribunal- sobre la preparación de programas para los nuevos grupos escolares..., etc. Estas decisiones reflejan una lógica interna de representación de la propia vida con objetivos y contextos diferentes. Un análisis pormenorizado de este tipo de fuentes, junto con otro tipo de documentos, - como los expedientes de depuración-configuraría un modelo de trabajo desde el que interpretar dichas decisiones y reconstrucciones, con el fin de estudiar las transformaciones de las identidades profesionales del magisterio.

\section{CONCLUSIÓN}

Los expedientes del concurso-oposición para Direcciones de escuelas graduadas de seis o más secciones convocada en 1932 constituyen una fuente original para el estudio de un grupo esencial del magisterio primario republicano. La relevancia de estas Direcciones de graduadas en el contexto de la renovación pedagógica republicana hizo de este proceso selectivo un atractivo instrumento para la creación de un grupo selecto de docentes, los cuales debían estar al frente de los grandes grupos escolares que, a su vez, representaban uno de los núcleos de la reforma educativa. Dicha selección estaba fundamentada en una exigencia narrativa consistente en la construcción de un expediente personal, que constituye la particularidad documental de la fuente: los opositores debían representar libremente su vida profesional y avalarla documentalmente, sin ninguna pauta estipulada. Si analizamos las condiciones de producción de dichos expedientes, podemos sugerir una propuesta metodológica concreta para analizarlos: se trata de comprenderlos como una práctica de archivo de vida, lo que nos permite estudiar la representación de la identidad profesional que estos docentes elaboraban en el contexto de la oposición. Esto nos posibilita analizar sus discursos, sus prácticas confesas, sus afiliaciones, su autopercepción como docentes y sus ideales pedagógicos, todo lo cual era escenificado ante el tribunal mediante la reconstrucción de dichas identidades.

Hemos ejemplificado este marco interpretativo con la lectura del expediente-oposición de María Sánchez Arbós, interpretando sus decisiones 
y acentuando las coincidencias y los silencios con la lectura comparada de su Diario. Dicha lectura nos permite dar cuenta de la representación de una identidad profesional en el marco de estas oposiciones, asistir a la complejidad de este proceso y también codificar e inventariar los elementos que constituyen dicha identidad.

Nuestra propuesta permite también proyectar un estudio comparativo de la serie completa de los expedientes que conforman la oposición, lo cual permitiría, asimismo, el estudio de los modelos de construcción de estos archivos, los modos de producción de discursos e iconografías de la renovación pedagógica y los niveles de reflexión y apropiación de las teorías pedagógicas vigentes en un sector clave del magisterio primario republicano. Todo ello, sin perjuicio del valor testimonial y textual que los elementos de cada expediente puedan tener para la reconstrucción de la cultura escolar y de la intrahistoria de la escuela durante las primeras décadas del siglo XX. Sin embargo, las posibilidades metodológicas de esta propuesta no acaban en esa lectura comparativa. Dicho análisis permite planificar la triangulación de otro tipo de fuentes autobiográficas — como en efecto lo es el Diario - para dar cuenta de la transformación de las identidades profesionales del magisterio en diversos contextos y a lo largo del tiempo. Puede programarse, de este modo, un modelo de análisis sistemático con el que sacar rendimiento a esta fuente tan singular.

\section{Nota sobre el autor}

Carlos Menguiano Rodríguez es licenciado en Filosofía (2013) con un Máster Universitario en Estudios Avanzados en Filosofía (2014). Actualmente realiza estudios de Doctorado en Educación (en la rama de «Investigación y Política en Educación: Perspectivas históricas y metodológicas») en la Universidad de Alcalá, en condición de contratado predoctoral perteneciente al proyecto «La fotografía publicada como representación de los cambios y las continuidades en la cultura escolar (1900-1970)», [EDU2014-52498-C2-1-P], que es financiado por el Programa Estatal de Fomento de la Investigación Científica y Técnica de Excelencia, Subprograma Estatal de Generación de Conocimiento, incluido en el Plan Estatal de Investigación Científica y Técnica y de Innovación 2013-2016 del Ministerio de Economía, Industria y Competitividad. Lo hace como beneficiario 
de la ayuda para contratos predoctorales FPI [BES-2015-075107] otorgado a dicho proyecto por el mismo Ministerio con cofinanciación del Fondo Social Europeo. Está adscrito al Departamento de Ciencias de la Educación como Personal Investigador y es también miembro del Grupo de Investigación «Claves históricas y comparadas de la educación. Género e identidades» de la Universidad Complutense de Madrid. Su labor investigadora se centra en el análisis de la construcción de las identidades profesionales del magisterio español durante el primer tercio del siglo XX.

\section{REFERENCIAS}

Artières, Philippe. "Arquivar a Própia Vida». Revista de Estudos Históricos 11, no. 21 (1998): 9-34.

Llopis, Rodolfo. La revolución en la escuela: Dos años en la Dirección General de Primera Enseñanza. Madrid: Biblioteca Nueva, 2005.

Lozano Seijas, Claudio. La educación republicana 1931-1939. Barcelona: Universidad de Barcelona, 1980.

Luzuriaga, Lorenzo. La escuela nueva pública. Buenos Aires: Losada, 2002.

Mainer Baqué, Juan. La forja de un campo profesional. Pedagogía y Didáctica de las Ciencias Sociales en España (1900-1970). Madrid: Consejo Superior de Investigaciones Científicas, 2009.

Molero Pintado, Antonio. La reforma educativa de la Segunda República Española. Primer bienio. Madrid: Santillana, 1977.

Pérez Galán, Mariano. La enseñanza en la Segunda República. Madrid: Biblioteca Nueva, 2011.

Pozo Andrés, María del Mar del. Currículum e identidad nacional. Regeneracionismos, nacionalismos y escuela pública (1890-1939). Madrid: Biblioteca Nueva, 2000.

Pozo Andrés, María del Mar del. «Los institucionistas y la política educativa española (1898-1936): proyectos y realidades». En La Institución Libre de Enseñanza y Francisco Giner de los Ríos: Nuevas perspectivas. Vol. I. Reformismo liberal. La Institución Libre de Enseñanza y la política española, editado por Javier Moreno Luzón y Fernando Martínez López, 256-291. Madrid: Publicaciones de la Residencia de Estudiantes, 2012.

Pozo Andrés, María del Mar del. "La construcción de la categoría "Maestra Republicana": La tipología generacional como propuesta». En Las Maestras de la República, editado por Elena Sánchez de Madariaga, 236-270. Madrid: Catarata, 2012. 
Pozo Andrés, María del Mar del. Justa Freire o la pasión de educar. Biografía de una maestra atrapada en la historia de España (1896-1965). Barcelona: Octaedro, 2013.

Samaniego Boneu, Mercedes. La Política Educativa de la Segunda República durante el Bienio Azañista. Madrid: CSIC, 1977.

Sánchez Arbós, María. Mi Diario. Zaragoza: Gobierno de Aragón y Caja Inmaculada, 2006.

Sánchez Arbós, María. Una escuela soñada. Madrid: Biblioteca Nueva, 2007.

Viñao Frago, Antonio. Innovación pedagógica y racionalidad científica. La escuela graduada pública en España (1898-1936). Madrid: Akal, 1990.

Viñao Frago, Antonio. "Las autobiografías, memorias y diarios como fuente histórico-educativa: tipología y usos». Sarmiento 3 (1999): 223-253.

Viñao Frago, Antonio. «La Dirección Escolar: un análisis genealógico-cultural». Educação 27, no. 2 (2004): 367-415. 